\title{
DEVISTA TEMAS EM EDUCAÇÃO
}

\section{O INATO E O APRENDIDO: A EFICÁCIA DO HABITUS NO CAMPO ESCOLAR}

\author{
Geraldo de Andrade Fagundes [*] \\ Ivone Fernandes Morcilo Lixa [**]
}

[*] e-mail: geraldofagundes.arts@ gmail.com [**] Doutora - Professora titular do Curso de Direito da Universidade Regional de Blumena (FURB)- ORCID: https://orcid.org/0000-0002-3822-4523 - e-mail: iflixa@furb.br

\section{RESUMO}

Embora se tenha pesquisado muito sobre escola, há aspectos pouco explorados acerca das ações explícitas ou implícitas que norteiam a prática dos indivíduos no espaço escolar. Para tanto, esse artigo tem por pretensão, buscar em Pierre Bourdieu (1930-2002) um testemunho sociológico a partir dos fundamentos teórico-metodológicos de campo social e habitus como meios reflexivos para a compreensão da atuação cotidiana para analisar as disposições escolares. Através da análise de observação participante tendo como foco duas turmas dos anos iniciais e uma turma dos anos finais em duas Escolas da Rede Pública do Município de Blumenau, estabelecemos que a força do habitus em um campo social como a escola, funciona como um capital, ou seja, como instrumento socialmente reconhecido em uma apropriação ligada aos bens "simbólicos" interiorizados de forma poderosa através das práticas escolares. A reflexão revela que alguns processos de aprendizagem se inserem através de uma percepção com base na prática transformada em costumes, ou seja, comportamentos inveterados propensos por situações semelhantes. É, portanto, reconhecível que as intenções e desejos dos indivíduos no curso do processo de escolarização, se manifestam de forma recursiva na prática do corpo, agindo sobre si e sobre os outros.

Palavras-chave: Campo Social. Escola. Habitus. Simbólico. 


\section{INTRODUÇÃO}

Com o tempo, certas legendas reducionistas vêm sendo inventadas e/ou transformadas em 'mitos' difíceis de serem desfeitos, no que diz respeito às disposições no campo escolar em relação às estruturas objetivas. Para compreender o que parece ser um contexto compreendido quando visto sempre a partir das representações coletivas, a escola por ser um espaço tão comum, muitas vezes esconde o indivíduo e as suas condutas. Nesse sentido, indivíduos partilhando do mesmo campo, na medida em que dividem a condições semelhantes ou homólogas de produção, isto é, à experiência de uma mesma posição na distribuição dos recursos simbólicos, imprimem em ações que se corporificam em forma de Habitus partilhados por condições semelhantes.

É necessário colocar em evidência os principais agentes da teia educativa, quais sejam, os alunos e os professores que, distinta e diariamente, se vestem da própria ação para atuar no campo da escola. Para este objetivo irei desenvolver esse trabalho em três momentos: um quadro-síntese do conceito de Campo Social com sua história, uma breve conceitualização da noção de Habitus e por fim, a exposição desses conceitos como influenciadores no comportamento dos indivíduos no espaço escolar.

É importante destacar que os alunos observados, estão em espaços partilhados de experiências e principiante contribuem para o desenvolvimento de uma ética de comportamento traduzível no esforço diário nas disposições da escola. A partir da premissa de não estabelecer um corpo único de escolha como desejável para a experiência de pesquisa, mas tendo a consciência das condições em que incidem os efeitos e limites desta experiência, buscamos num duplo eixo, duas escolas da Rede Pública de Ensino de Blumenau a partir das seguintes turmas: $2^{\circ}$ e $3^{\circ}$ (anos iniciais) e $9^{\circ}$ (anos finais) com alunos que trazem certa proeminência da subjetividade individual e a exacerbação de padrões regularmente estáveis de comportamento. Para poder desenvolver um quadro de análise sobre as epistemologias dos comportamentos, utilizamos a observação participante que nos pareceu a metodologia mais adequada, pois, permitiu ao pesquisador uma análise mais delimitada e específica nas incursões constantes do fazer dos alunos tendo um papel de espectador do objeto observado (GIL, 2006; BRANDÃO, 1999).

O pesquisador empregou na cultura compartilhada, a observação das imagens rituais desenvolvidos nos cultos. Isto significa "descrever o rito na própria consumação do rito" (Bourdieu, 2005: 131). Por isso, foi tomado um cuidado aos dados observados contado com 
uma análise mais delimitada e específica das variáveis e das relações de dependência interrelacionadas dos discursos, ou seja, que encontrou uma relação razoável entre os acordos, oposições do que foi observado, já que "[...] não é possível evitar atarefa de constituir o objeto sem abandonar a busca por esses objetos pré-construídos” (Bourdieu, 1999, p. 47). Nossa suspeita inicial com relação à noção do que pensar e do fazer entre os professores e alunos, se estabelece pelo conversar interno na privacidade da mente, naquilo que Goffman, (1981), designou por 'auto-conversação' (um diálogo com sigo mesmo) e que estabelece 'corporeidade' em suas ações como indicado por Julia, (1995); Viñao, (1998). Essas ações, aliás tanto mais eficientes quanto menos explicitadas - só pode ser adequadamente percebida enquanto acordo por seus resultados práticos. Orientados pelas estratégias de sobrevivência no campo, esses indivíduos enfrentam constantemente movimentações, compreendem a vida escolar parcialmente em meio a um sistema que apaga as próprias pegadas. Para refazer essas pegadas, buscou-se articular os conceitos de campo social e habitus com os quais Pierre Bourdieu (1930-2002), desenvolveu uma relação dialética entre condutas individuais propelidas socialmente. A preocupação inicial de Bourdieu era conectar essas condutas com o conceito de campo social e superar o limite sócio circunstancial (condição de classe) perpassado por um confronto crítico com o agente $^{1}$ (sujeito do campo) partilhado supostamente em condições semelhantes e alinhá-lo diante da $d o x a^{2}$ escolar.

Esse acordo nunca explicitado - acordo esse, aliás, tanto mais eficiente quanto menos explicitado - só pode ser adequadamente percebido enquanto acordo pelos seus 'resultados práticos'. Portanto, o passo essencial é perguntar: como o fenômeno conhecido como habitus em um campo social como a escola se torna força reprodutora de modos de interiorização dos comportamentos de práticas escolares? Como são fabricados e transmitidos os comportamentos, ou seja, como alguém toma para si (incorporando-o) um padrão (hábito) que não era seu, e o aplica a ponto de ser por ele guiado quase que inconscientemente? É possível encontrar resposta em certa medida, em autores como Durkheim (1977), nos processos de socialização ou na coerção do fato social, ${ }^{3}$ Mauss (1974), com o uso do "corpo" e a construção cultural própria de cada sociedade de forma diferenciada ou em Lévi-Strauss

1 Os indivíduos são agentes à medida que atuam e que sabem, que são dotados de um senso prático, um sistema adquirido de preferências, de classificações, de percepção (BOURDIEU, 1996, p. 44).

2 " "...] um ponto de vista particular, o ponto de vista dos dominantes, que se apresenta e se impõe como ponto de vista universal" (BOURDIEU, 1983, p. 120)

3 "É fato social toda maneira de agir, fixa ou não, suscetível de exercer sobre o indivíduo uma coerção exterior; ou, ainda, que é geral ao conjunto de uma sociedade dada e, ao mesmo tempo, possui existência própria, independente das manifestações individuais que possa ter." (DURKHEIM, 2002. p. 11). 
com o "momento de objetivação indispensável". "Contudo, encontramos um resgate a discussão em torno da noção de habitus na expressão weberiana de stahthartes Gehäuse (rija crosta de aço) em que Weber (2007, p. 20) afirma ser uma "cápsula de aço", capa, concha etc.; decidimos pela palavra crosta por manter algo de aversivo em sua conotação. Gesinnung = disposição (em vez de: atitude, mentalidade, convicção, etc. Mas onde estaria o conceito de crosta de aço se encontra com o a noção de habitus em Weber? Laval (2006), resgata a discussão em torno da expressão weberiana, afirmando que o importante é saber o quer dizer Weber quando ele utiliza a expressão 'gaiola de aço ou crosta de aço'.

Que ideia ele quer passar para nós quando afirma que os homens do futuro, os últimos homens viverão nesta caixa ou neste caso? Esta gaiola é uma expressão colorida do que ele chama de habitus capitalista, correspondendo ao "espírito do capitalismo". O ponto importante no pensamento de Weber reside no fato de que esse habitus foi primeiro constituído como um comportamento significativo e justificado, que foi baseado em uma certa relação com o Deus calvinista. (LAVAL, 2006, p. 1).

Porém em Weber, as ideias religiosas do "espírito" do capitalismo poderiam ser não uma crosta, mas um manto leve sobre a sociedade, como sugere o título, "o aprendido". O manto leve transformou-se numa "rija crosta de aço". ${ }^{5}$ Em outras palavras, uma espécie de habitus (em busca do lucro) que, por inculcação, passa a dominar a todos. Trata-se de um habitar de Mobilidade de peso, uma vez que na análise weberiana traz o repouso da dominação sobre o capital. De acordo com Héran (1987, p. 390), a leitura werberiana de habitus, deve ser o "elemento motor da "invenção"" sociológica do habitus por Bourdieu, ocorrido uns 20 anos atrás, e não, como se supôs recentemente, em uma improvável frequentação de Thomás de Aquino. Em Weber, porém, procurou dar uma resposta religiosa para fundamentar o que o "espírito" do capitalismo e que deveria ser, não uma gaiola, mas um manto leve sobre a sociedade, diz Weber (2004, p. 166). Antes de partir para um quadro teórico mais específico, que possa captar a dinâmica do habitus na escola, propõe-se uma visita ao conceito de campo social e, mesmo que de modo breve, uma análise de como funciona sua estrutura.

\section{A GENEALOGIA DO CONCEITO DE CAMPO}

\footnotetext{
4 “A ciência social supõe necessariamente o momento de objetivação e são ainda as aquisições do objetivismo estruturalista que tornam possível o ultrapassamento que ele exige." (BOURDIEU, 2009, p. 24). Defendendo o que chamará de "estruturalismo genético", Bourdieu reintegra a experiência dos agentes como fazendo parte da realidade social sem, no entanto, aí procurar toda a verdade de suas ações, que só tomam sentido em um sistema de relações estruturado e hierarquizado.

5 Tradução proposta por Antônio Flávio Pierucci em Weber (2004).
} 
A preocupação com o espaço escolar despontou como um dos estudos mais fecundos na área da educação nas últimas décadas. Até o início dos anos 70 estudos baseados na observação da sala de aula, tinham como metodologia de abordagem a etnografia, modelo de observação que utilizava esquema de "análise de interação", tendo a Psicologia Comportamental como princípio. Alguns desses registros foram reunidos em publicações como: Mirrors for behavior, de Simon e Boyer (1970), e Explorations in Classroom Observation, de Michel Stubbs e Sara Delamont (1976). Tais publicações, serviram como registros do comportamento e da maneira como os professores e alunos interpretavam as práticas educativas. Portanto, vamos colocar a escola como instância que transcende os indivíduos, tornando-se uma instituição com certa autonomia, escondendo, dessa forma, os interesses das lutas num espaço que Bourdieu chama de campo social. A noção de campo formulada por Bourdieu (2001) foi apresentada como o resultado do processo de diferenciação do mundo social em espaços menores como campo científico, campo literário, campo jurídico, entre outros.

Com o tempo, o conceito de campo deixou um largo espaço para todos os tipos de análises interpretativas e de rótulos na tentativa de superá-lo ou de tentar atribuir-lhe imprecisão. Um campo é marcado por indivíduos dotados de um mesmo habitus ou de uma orientação direta em que se movimentam no espaço como jogadores, cujas posições depende do acúmulo de capital adequado ao campo que cada indivíduo adquire. Mas o fato é que o frequente emprego do conceito de campo em pesquisas demonstra o quanto ele está presente na produção sociológica dos trabalhos acadêmicos entre várias correntes das ciências sociais.

O que ocorre muitas vezes, é seu uso indevidamente situado, creditado apenas como conceito generalista ou tido somente como esfera social da construção de classe. É preciso ter clareza de que houve um longo itinerário trilhado no conceito de campo antes de se tornar peça basilar nas investigações de Bourdieu. Esse conceito foi usado em toda a sua obra, aparecendo pela primeira vez no livro Sociologie de l'Algérie (1958) e, em seguida, publicado na revista Les Temps Modernes (1966). Mas é possível encontrá-lo com maior frequência nos livros O senso prático (1980). Questões de sociologia (1983) e Meditações Pascalianas (1997). A teoria geral de campo, adotada por Bourdieu, teve influência de autores como Max Weber (1864-1920) que aplicou essa noção à área das relações humanas como o conceito de "tipo ideal", em que nem todo contato humano é tido como social, mas apenas como um comportamento que se orienta pelo comportamento de outras pessoas no que diz respeito à racionalidade (WEBER, 1995). Contudo, examinando os escritos de Weber, Bourdieu (1997) avalia que a questão fundante de um campo não serve de modelo para todos os campos, bem 
como que tal modelo teórico não pode ser examinado de forma isolada, em si e por si mesmo, mas sim consubstanciado a outros campos.

Segundo Bourdieu (1997), é na relação dialética agente/campo que se encontra o princípio das práticas sociais, das estruturas e das "relações objetivas", que tornam o campo social diferente do conceito de sociedade, pois, para Bourdieu (1997) “[...] uma sociedade diferenciada não se encontra plenamente integrada por funções sistêmicas, mas, ao contrário, é constituída por um conjunto de microcosmos sociais dotados de autonomia relativa" (apud CATANI, 2011, p. 192). Já o campo é definido por Bourdieu (1982) como um espaço estruturado e internalizado de forma sistêmica, construído por relações sociais dotadas de certa autonomia. Essa lógica se impõe pela característica da própria condição do campo, uma vez que a falta de combate em um campo transformá-lo-ia em um aparelho, até o ponto de destruí-lo, pois, todo campo é “[...] um campo de lutas para conservar ou transformar esse campo de forças" (BOURDIEU, 2008, p. 64). Por ser um espaço de incorporação e, principalmente, de disputas de posições, exigindo certa relação entre igualdade e diferença, o campo oferece elementos para entender, na sua concretude, os papeis sociais. Bourdieu (1983) busca também reelaborar o quadro teórico-metodológico de análise do campo social, tentando ultrapassar as diferenças entre o conceito de campo social e sociedade, a fim de escapar, ao mesmo tempo, a possíveis contradições e limitações. Nessa empreitada, Bourdieu ganha, de certa forma, interlocutores da sua obra como Lahire (2002), que emerge com vigorosa contribuição para o conceito de campo. Em publicações mais recentes, Lahire extrai elementos relativos ao conceito de campo a partir dos artigos Quelques propriétés des champs (1976), Questions de sociologie (1980) e Lechamp li éraire (2002), descrevendo-o como

[...] um microcosmo incluído no macrocosmo constituído pelo espaço social (nacional) global. [...] A cada campo corresponde um habitus (sistema de disposições incorporadas) próprio do campo (por exemplo, o habitus da filologia ou o habitus do pugilismo). Apenas quem tiver incorporado o habitus próprio do campo tem condição de jogar o jogo e de acreditar n (a importância d) esse jogo. (LAHIRE, 2002, p. 47-48).

Lahire (2002) faz um estudo relacionando o que é exigido pelo campo. Porém, questiona: o que é distribuído de forma igual e desigual no campo? Como podemos avaliar isso de modo coletivo e particular? Antes de tudo, o que motivaria os agentes a buscarem estratégias para a sobrevivência no campo? Lahire (2002, p. 51) faz uma extensa crítica do conceito de campo, afirmando que nem tudo pode ser nele incluído uma vez que isso "[...] pode constituir um obstáculo ao conhecimento do mundo social (sobretudo quando o campo 
se torna o alfa e o ômega de toda a contextualização das práticas)". Afirma também que nem todos os espaços têm os atributos de um campo a exemplo da família, e que o conceito de campo serviria para mapear "grandes palcos", mas não para olhar "os que montam esses palcos" (LAHIRE, 2002, p. 50). Suas preocupações são pertinentes, no entanto, há um senso prático que permite dentro do campo, “[...] operar atos de conhecimento prático, fundado no mapeamento e no reconhecimento de estímulos condicionais e convencionais a que os agentes estão dispostos a reagir" (BOURDIEU, 2001, p.169) na medida da própria consciência. Lahire (2002) em seus apontamentos, não observa que o conceito de campo parte de uma perspectiva mais dinâmica em que o campo, servido de certa autonomia, cria suas próprias mudanças ao atualizar as próprias demandas. De igual modo, Bourdieu não exclui a família, tampouco o agente que não se adapta a ela, pelo contrário, o conceito de campo abarca todos os agentes mesmo que isso signifique nunca ser por "[...] inteiro o sujeito de suas práticas" (BOURDIEU, 2001, p. 169) em razão do habitus que penetra nas mentes mais lúcidas e conscientes. Esse sentido é o que dá consistência à prática, uma vez que "[...] nunca podemos apreender um suposto substrato de consciência enquanto tal [...]”, mas "[...] somente a consciência de tal ou qual coisa. [...] como elemento de uma realidade subjetiva interior" (BERGER; LUCKMANN, 2004, p. 37). Berger e Luckmann (2004) nos lembram do caráter intencional da consciência empregada nos espaços em que ocorrem lutas para obter posição e que não depende do entendimento da realidade, nem do que se repete ou do que é raro. "Dito de outro modo tenho consciência de que o mundo consiste em múltiplas realidades. Quando passo de uma realidade a outra, experimento a transição como uma espécie de choque" (BERGER; LUCKMANN, 2004, p. 38), um deslocamento no campo, mas sem perder a doxa que já foi aprendida. Assim, a consciência do agente é seu campo e, como tal, possui suas transformações e limitações. Os campos não são espaços de não consciência como subentendido por Lahire (2002) em suas análises.

E, a propósito, a crítica de Lahire é uma prova do campo agindo em sua plenitude dando condição para sua existência. E, ajustado ou não, o campo promove o encontro de divergências entre seus agentes e, ao mesmo tempo, está justificado pelos nomos (leis), princípios que se encerram no próprio campo. O campo dispondo do recurso do nomos, não autoriza oposição entre seus jogadores, logo “[...] do ponto de vista constitutivo de um campo, torna-se completamente inviável assumir a seu respeito um ponto de vista externo: por jamais ter sido postulada desse modo, tal 'tese', não pode ser contestada" (BOURDIEU, 2001, p. 117). Esse é um dos motivos pelos quais agentes experientes ou que detêm uma posição privilegiada, monopolizam a autoridade organizando à sua maneira a estrutura e as 
estratégias de conservação em oposição aos novos que procuram se posicionar no sentido de subverter o espaço ou resistir à dominação.

Não se trata de um antagonismo de forças entre agentes, pois nem todos estão conscientes dessa condição. Lutam porque há estímulo criado pela própria disposição ao campo, "[...] um sentido do jogo, ordinariamente designado como um 'espírito' ou um 'sentido'[...], que praticamente jamais é posto ou imposto de maneira explícita" (BOURDIEU, 2001, p.21). São as disposições incorporadas pelo habitus que se ajustam (ORTIZ, 1983; NOGUEIRA; NOGUEIRA, 2002, 2006; SETTON, 2002). É por esse motivo que "[...] ele (o agente) o entende num sentido bastante razoável, sem distância objetivante, como sendo algo evidente, justamente porque ele se encontra enredado nele (o campo)" (BOURDIEU, 2001, p. 174) em uma espécie de ilusão da compreensão imediata. Essa estrutura é incorporada de acordo com a percepção do agente, que tem suas relações pautadas no que Bourdieu (1996, p. 258-259) chamou de 'illusio', “[...]condição como o produto do funcionamento de qualquer campo".

Essa crença é compartilhada, portanto, integrante de um campo cujo encantamento faz parte de um microcosmo vivido como evidente. Mas essa semiconsciência não impede que aconteça o embate, pois, um novo agente tende a entrar no campo de maneira forçada em disputa com quem está dominando o espaço ao passo que este último tenta manter o monopólio da dominação e, se possível, excluir ou inferiorizar a concorrência. A partir do momento em que se estabelecem os jogadores, o próximo passo é definir o objeto de interesse que se tornará o objetivo de luta para que as pessoas dotadas de habitus estejam prontas para disputar o jogo (BOURDIEU, 1984).

Apesar de os interesses dos agentes possuírem limites distintos, há uma cumplicidade entre eles pelo simples fato de estarem no jogo e por fazerem parte da disputa, e os que participam colaboram com a reprodução do jogo, produzindo "[...] a crença no valor do que está sendo disputado "Os recém-chegados devem pagar um direito de entrada que consiste no reconhecimento do valor do jogo [...] e no conhecimento (prática) dos princípios de funcionamento do jogo" (BOURDIEU, 1984, p. 121-122). Os limites de subversão não são ameaças passíveis de comprometer o campo, mesmo porque as resistências servem para formular e reformular novas disposições entendidas como princípios ativos da vida coletiva.

Assim, o limite de um campo é o limite dos seus efeitos, portanto, a sutileza das suas tramas. Existe aí uma adaptação supraposicional entre o inconsciente-condicionado e o consciente-calculado que confere uma relativa autonomia às tramas de práticas semiconscientes e mimetizadas pelos agentes. No nível da dominação do corpo, o habitus se 
impõe aos organismos com a mesma incisividade com que coage a consciência manifestada nas mudanças graduais (FOURNY; EMERY, 2000; WIDICK, 2018). Determinadas ações, justapostas, distribuem a porção disponibilizada pelo esquema em um estado axiológico compreendido pelos princípios que naturalizam a ocupação do lugar que cabe a cada um na sociedade. Ou seja, é a partir do caráter objetivo que os agentes se posicionam em um movimento da 'causalidade' 'puramente natural', mas, para além disso, no sentido da prática no corpo (héxis). ${ }^{6}$

E é na ação que conhecemos a consciência daquele que existe, de modo que não há elemento cindido em oposição entre o dado sensível no ato de fazer a coisa, a res extensa (substância corpórea), e o habitus do corpo. Como a concepção cartesiana de corpo-máquina, o corpo se mobiliza sem a ajuda de uma consciência, ou seja, não há uma intencionalidade, mas sim uma matriz redutora de consciência do corpo para a ação. A questão é: não está dado o significado exato da intencionalidade do corpo nem dos objetos de desejo, mas é possível identificar quais são os intercâmbios das práticas codificadas objetivamente através do habitus.

\section{A PROJEÇÃO DO HABITUS}

Para dar conta da relação indivíduo/campo social, Bourdieu (1982) encontrou no conceito de habitus as conexões necessárias para compreender o significante do capital psíquico encontrado na relação, agente/estrutura. Esse conceito viria a se tornar elementochave da sua teoria marcando profundamente toda a sua sociologia. A palavra habitus vem de uma vertente aristotélica que remonta ao século XIII. Encontramos essa noção em variados autores, como por exemplo: Marcel Mauss na obra As técnicas do Corpo (1934), Max Weber em A ética protestante e o "espírito" do capitalismo (1904-1905) e em Norbert Elias, na obra “O processo civilizador” (1993) no que remonta o habitus e a construção histórica. Em Pierre Bourdieu, o primeiro registro encontra-se no artigo: Célibat et condition paysanne. Études rurales (1962), que revela a incorporação de mecanismos sutis que transformam as dinâmicas interiores dos homens, adquiridos da sua posição e reprodução social. Nesse estudo, Bourdieu analisa os arranjos entre famílias que fazem do matrimônio um meio de sobrevivência: os ‘arranjos' familiares em Kabilia (Argélia), que se aproximam da relação com Béarn (França), sua região natal e, em seguida, faz o mesmo no artigo Travail et travailleurs en l'Algérie (1963), publicado parcialmente em Português com o título: 'O desencantamento do mundo'

${ }^{6}$ O conceito foi traduzido da palavra grega héxis, que Aristóteles definiu como “[...] as disposições adquiridas do corpo de da alma" (DUBAR, 2005, p. 77). 
Scolastique, de Erwin Panofsky (1982). Nesses estudos, Bourdieu constata que o habitus resulta de experiências fundamentais de estruturas internalizadas e externalizadas como disposições internas que partem de parâmetros e limites dentro de um grupo particular por meio da socialização no campo. Assim, o habitus se mostra adequado para compreender as ações sistemáticas que muitas vezes foge da compreensão dos indivíduos por estar tão profundo e intenso confundido com algo "inato" que, quem está nele, vê como absurdo todo aquele que está fora. É uma espécie de encantamento entre seus agentes dentro da estrutura; embora o habitus não seja uma estrutura inata ao campo, funciona como uma categoria $a$ priori no sentido determinado das apreensões e práticas subsequentes à sua formação, mudando sem cessar em função das novas experiências. As disposições engendradas pelo habitus são submetidas às transformações permanentes e jamais são radicais, pois, operam a partir do estado já assimilado anteriormente sem a distância objetivante do mundo e no futuro que aí se anuncia (o que o distingue de uma mensagem momentânea sem história).

Para fazer um uso objetivo da dinâmica do habitus num campo social, vale a pena começar por esta citação de Weber (1999, p. 4): "Não é preciso ser César para compreender César". Pelo dito de Weber, compreender alguém não pressupõe estar no corpo desse alguém mediante uma incorporação psíquica, mas estar numa posição psíquica análoga a esse corpo. Podem-se reconhecer os que partilham dos mesmos códigos depositados na experiência primeira ou ainda aqueles que não experienciaram uma circunstância, mas está no mesmo campo. Em tese, isso é possível porque as ações tendem a se orientar e se tornar manifestas principalmente para aqueles cujas respostas são familiarizadas por conta de ações dotadas de sentido. Isso é compreensível

[...]em alguns casos de processos psicofísicos; em outros, só se apresenta para o especialista na matéria; processos místicos e, com isso, não comunicáveis de modo adequado por palavras, não são plenamente compreensíveis para aquele que não tenha acesso a tais experiências. (WEBER, 1999, p. 130-131).

Por eles mesmos aprendidos e transmitidos como sociogênese ${ }^{7}$ da motivação objetiva que em essência, é transcognitiva, transcultural e transistórica, mantida e/ou eventualmente transformada a partir da contínua acomodação agente/estrutura. A ação, nesse caso, tem como motivo de interesse a iniciativa ou, segundo Weber (1995), traços específicos típicos da dominação que encontra

\footnotetext{
7 O processo de sociogênese é relativo ao Estado como entidade modeladora dos afetos e das atitudes individuais (ELIAS, 1993).
} 
[...] obediência a uma determinada ordem, pode ter o seu fundamento em diversos motivos de submissão: pode ser determinada diretamente de uma constelação de interesses, ou seja, de considerações racionais de vantagens e desvantagens (referentes a meios e fins) por parte daquele que obedece; mas também pode depender de um mero costume, ou seja, do hábito cego de um comportamento inveterado; ou pode, finalmente, ter o seu fundamento no puro afeto, ou seja, na mera inclinação que repousasse apenas nesses fundamentos seria relativamente instável [...]. (WEBER, 1995, p. 349).

Weber detecta uma "dominação legal", um estatuto legitimado corretamente de acordo com aquilo que conhece, e o que conhece é a obediência, “[...] não em virtude do seu direito próprio, mas à regra, que estabelece quem e em qual medida se deve obedecer. Aquele que manda também obedece a uma regra no momento em que emite uma ordem" (WEBER, 1995, p. 350). A “dominação legal”, na qual os agentes obedecem às ordens corretamente dispostas e continuadamente instaladas, está mais no senso prático ${ }^{8}$ de um pensar evidente do que nas determinações impostas. Em outras palavras, a representação do agente vem imbuída de razão, que tende a parecer como necessária ou até mesmo natural em determinadas ações.

\section{A INSTAURAÇÃO DO HABITUS NO CAMPO ESCOLAR}

A gramática do habitus é a prática, por conseguinte, possui infinidades de situações renovadas, que se mostram princípio ativo na orientação dos agentes no sentido de novos ajustes e em uma visão descontinuísta e sempre atualizada da lógica. Nesse sentido, faz-se necessária uma busca nas instâncias mais diminutas das disposições escolares em que o habitus se encontra escondido nas mais simbólicas e sedimentadas das projeções, pois essas regiões são complementadas por projeções construídas historicamente como uma cultura indubitável, "[...] algo dado aos sujeitos, como um legado imposto aos mesmos" (SACRISTÁN, 1999, p. 74), conforme ações rotineiras que "[...] têm uma continuidade temporal inevitável e não [são] um simples passado ao qual se olha como um objeto petrificado, pelo contrário, continua sendo operacional, organizando a ação dos membros que compartilham uma cultura" (SACRISTÁN, 1999, p. 73).

Um exemplo disso está na economia das práticas escolares e principalmente, nos primeiros anos da educação básica em que os alunos formam fila por ordem de tamanho ou, desejosos por posição, não sabem sobre a magia da pulsão desse desejo. Como não há separação entre eles e ambos fazem parte de uma contínua dialética que age a partir da

\footnotetext{
8 O senso prático é o que permite agir de maneira adequada (ôs dei, dizia Aristóteles) sem interpor ou executar um 'é preciso', uma regra de conduta. Maneiras de serem resultantes de uma modificação durável do corpo operada pela educação, as disposições atualizadas pelo corpo permanecem despercebidas enquanto não se convertem em ato, e mesmo então, por conta da evidência de sua necessidade e de sua adaptação imediata à situação (BOURDIEU, 2007, p. 169-170).
} 
mesma interiorização e da mesma realidade social, a mente e o corpo passam a ter as mesmas respostas aos estímulos.

Aparentemente um ato simples de conquista de espaço, mas para tal ação, faz-se necessária uma cadeia de significantes e desejos que pertencem ao pensar semiconsciente aplicável na reprodução da mobilidade social. Há exemplo disso mesmo em atividades lúdicas e aparentemente inocentes, como a brincadeira do silêncio, tão usual na escola em que o aluno(a) mais quieto(a) em sala é escolhido(a) para comandar a brincadeira e ter a preferência de escolher seu sucessor que fará a mesma coisa. Essa atividade é incorporada pelo sujeito e se reflete em sua prática objetivada. Obtém-se duas coisas com essa atividade: o silêncio tão esperado pelo professor(a) e a justeza semiconsciente da criança em relação à obediência. De fato, os exercícios escolares como o 'faz de conta', sem móvel (econômico) real, constituem a ocasião de adquirir, por acréscimo, “[...] a disposição escolástica e o conjunto dos pressupostos inscritos nas condições sociais que os tornam possível" (BOURDIEU, 2001, p. 24). Apesar de ter toda a aparência de ação racional, na verdade, "As condições para o cálculo racional praticamente nunca são dadas na prática: o tempo é contado, a informação é limitada, etc. No entanto, os alunos fazem com muito mais frequência do que se agissem ao acaso, 'a única coisa a fazer'” (BOURDIEU, 2004, p. 23). Esse poder impõe sentido ao mundo e é na adequação que ocorre as estruturas objetivas que sustentam as regras sociais.

Assim, fica o desejo dóxico de agir conforme a norma com a qual o poder simbólico ${ }^{9}$ de maneira implícita, normatiza o jogo social. Destacam-se como referenciais neste aspecto, exemplos que podem constituir-se como categorias de análise como o sujeito nomeado os "vigilantes" (os próprios alunos como células de controle das ações ulteriores). É possível encontrá-los em todas as etapas da vida escolar, sobretudo, nos anos iniciais em que não possui um comportamento encontrando na sua origem, nem na razão da decisão e nem na determinação mecânica da regra, mas na estrutura das práticas racionais motivadas pelo habitus (BOURDIEU, 2009).

Esses indivíduos são responsáveis por delatar qualquer tipo de comportamento que não faça parte das disposições orientadas pelas regras da sala já que uma parcela transgressora dos alunos rivais, ou, de meninos e meninas, entram em conflito com o corpo da escola. Notadamente são principalmente os mais jovens, agem dessa forma por fidelidade às regras por medo da punição ou, porque seu impulso condicionado encontra saída na

9 O Poder Simbólico é "[...] invisível o qual só pode ser exercido com a cumplicidade daqueles que não querem saber que lhe estão sujeitos ou mesmo que o exercem" (BOURDIEU, 1989, p. 7). 
repetição enquanto módulo de pulsão semiconsciente do desejo de aproximação com as disposições do campo. É uma forma de ajustamento (corpo educando corpo) que igualmente consagra seu próprio capital social diante da autoridade adulta. Nesse meio, encontramos também o arbitrário cultural que submete os alunos a uma dóxica ${ }^{10}$ escolar homóloga à cultura dominante e seus códigos miméticos. Entre as modalidades do arbitrário cultural, encontra-se também a linguagem, cujos principais problemas Bourdieu (2008) julga serem três, a saber: noções de gramaticalidade, de comunicação e de competência linguística. Na gramaticalidade, "[...] exerce uma competência social, a do locutor legítimo, autorizado a falar e a falar com autoridade" (BOURDIEU, 2008, p. 28) a partir da gramática dominante. A escola não exclui corpo, mas o conduz à elaboração de um processo de legitimação política do Estado, ao fim do qual os sujeitos falantes são levados a aceitar a língua oficial. Essa língua deve servir a instituições e revestir-se de funções que beneficiem a nação. No entanto, os sujeitos "[...] desprovidos de competência legítima se encontram de fato excluídos dos universos sociais onde ela é exigida, ou então, se veem condenados ao silêncio" (BOURDIEU, 2008, p. 42). É lícito incluir nessa modalidade a repetição dos códigos linguísticos, fórmulas ou mantras exigidos pelos professores que consagram

[...] todo o seu tempo àquilo que, para os outros, é uma. atividade secundária ou, pelo menos, de tempo parcial. Ele tem tempo; e tem o tempo a seu favor. Está em condição de dissolver na duração burocrática, na repetição devoradora de tempo e energia, todos os atos de força proféticos, isto é, descontínuos. É assim que os mandatários concentram um determinado poder, desenvolvem uma ideologia específica, fundada na inversão paradoxal da relação com os mandantes [...]. (BOURDIEU, 2004, p. 205).

Para essa reflexão, seria importante colocar o jogo da estrutura de dominação que subjaz às práticas repetitivas da cultura escolar. Trata-se de todos os tipos de ações reprodutivas que fazem parte da rotina dos agentes ou dos grupos que compõem o discurso mandatário como os exercícios de repetição para assimilação do que é ensinado nas mais prosaicas ações. Nesse contexto, o aluno permanece preso num mundo de repetição que não lhe permite negociar novas possibilidades de ação. Mergulhadas na imediaticidade das práticas, o efeito nas crianças ao longo do tempo é obscuro e não revela a tirania que acomoda corpo/mente, ou seja, os mecanismos pelos quais a realidade mostra-se à consciência. Nos anos iniciais como mencionado anteriormente, a linha que domina é a das

${ }^{10}$ É na experiência dóxica, afirma Bourdieu (2004, p. 144), “[...] que atribuímos ao mundo à crença mais profunda de todas as crenças (no sentido comum), já que ela não se pensa como uma crença. Tudo parece evidente, natural, tudo parece dado quando a percepção é construída de acordo com as estruturas do que é percebido". 
linguagens falada e escrita que conduz esquemas mais precisos no tocante ao desenvolvimento das operações sucessivas em “[...] falantes proficientes de uma dada língua, que produzem impensadamente atos de discurso corretos, de acordo com regras partilhadas de um modo inventivo, mas, não obstante, previsível" (WACQUANT, 2007, p. 66) que não expressa uma aptidão natural ou uma competência, mas sim um opus operatum (no sentido de poder) de um habitus culto. Assim, “[...] os que falam consideram os que escutam dignos de escutar e os que escutam consideram os que falam dignos de falar" (BOURDIEU, 1983, p. 6). Mesmo os que não falam legitimam aqueles que dominam os signos, os sentidos e as interpretações das falas. Isso é o que garante condição autorizada e sustenta a crença no feiticeiro e em sua magia

[...] continuada que se opera em meio às lutas incessantes entre as diferentes autoridades envolvidas, no seio do campo de produção especializada, na concorrência pelo monopólio da imposição do modo de expressão legítima, pode assegurar a permanência da língua legítima e de seu valor, ou seja, do reconhecimento que lhe é conferido. (BOURDIEU, 1996, p. 45).

Em um sentido social, não é diferente; os preceitos juridicista, na família/escola, estão dispostos à adequação social e condicionados a um habitus coerente, "[...] como se o habitus fabricasse coerência e necessidade a partir do acidente e da contingência" (BOURDIEU, 2009, p. 131). São incutidos desde a primeira infância, como condição para não se vislumbrar de onde poderiam vir as mudanças. Com efeito, isso equivale a ser 'alguém no nada', é reprodução daquilo que se acredita conhecer, produzido pelo desconhecimento, pois, entende-se essa lógica indutivamente. Ainda sobre a linguagem, por meio de uma comparação com a noção chomskyana de gramática, sugerem Bourdieu e Passeron (1975) que se trata de uma estrutura mental construída no falante competente, aquele que possui uma determinada língua com que possa falar do mesmo modo que todos os outros. Esse sujeito deve também ser (relativamente) criativo, (facilmente) adaptável e (axiomaticamente) previsível o que possibilitaria sua adequação a um conjunto de regras e de esquemas notáveis em um falante.

O habitus linguístico que pode operar não só abaixo do nível da fala silenciando as condições sociais de autonomia, mas também impossibilitando a consciência reflexiva com que o agente poderia tomar distância em relação ao seu escrever e, escrevendo, saber o que escreve. $\mathrm{O}$ aluno preso muitas vezes a uma forma gramatical subsumida à memorização de regras, não "[...] percebe que as palavras podem ter um sentido sem remeter a coisa alguma, ou seja, para produzir discursos formalmente corretos, mas semanticamente vazios" 
(BOURDIEU, 2008, p. 28). De fato, na ausência de objetivação na escrita, sobretudo decodificação quase jurídica correlata à constituição de uma língua oficial, '[...] as 'línguas' só existem em estado prático, ou seja, sob a forma de habitus linguísticos pelo menos parcialmente orquestrados e de produções orais desses habitus" (BOURDIEU, 2008, p. 33). Nesse estado de aplicabilidade, a fala e a escrita são bens culturais que conferem poder àqueles que as possuem, superioridade a quem fala bem e escreve bem, garantindo assim "[...] as maneiras ou os estilos legítimos e, de modo geral, todos os discursos destinados a se tornarem 'autoridade', fontes de 'referência obrigatória', e a serem citados como exemplos de "uso correto"” (BOURDIEU, 2008, p. 45). Em nome do reconhecimento da legitimidade e da informação transmitida, o habitus linguístico toma 'seu poder 'em nome daquilo que o define como disposição para o desconhecimento intransigente dos códigos da norma culta, uma vez que não faz parte das escolhas familiares de uso da língua, especialmente quando se trata das crianças com um menor capital cultural. Bourdieu (2008, p. 35), acusa a linguística de silenciar certas condições para autonomia em favor de um artefato teórico que "[...] conduz à elaboração, legitimação e imposição de uma língua oficial, de um sistema escolar que cumpre a função determinante de fabricar as semelhanças, das quais resulta a comunidade de consciência que é o cimento da nação".

Tratando-se da norma culta e do não reconhecimento de outras formas de expressão tidas como ilegítimas, a língua é considerada um veículo de poder, não só para a reivindicação do enunciado como para o anunciante. Desse modo, afirmaria " [...] o poder delegado do porta-voz cujas palavras (quer dizer, de maneira indissociável, a matéria de seu discurso e sua maneira de falar) constituem no máximo um testemunho, um testemunho entre outros da garantia de delegação de que ele está investido" (BOURDIEU, 2008, p. 87). Em outras palavras, ela não só torna importante o que é dito, mas quem as diz, e quem as diz é quem domina, seja ao falar seja ao escrever. A norma culta, portanto, é transformada em língua oficial, oficializada como único valor de sucesso e "[...] com certeza o suporte por excelência do sonho de poder absoluto" (BOURDIEU, 1998, p. 28).

Ao superar os primeiros anos de escolarização os estudantes chegam às séries finais que se encontram cada vez mais hierarquizadas em níveis cada vez mais suprimidos pela massificação das novas leis. Dessa forma, é muito comum transformar um sintoma em causa, atribuindo a dificuldade do aluno ao seu pouco esforço durante os anos anteriores. Aquilo que o habitus operava como uma segunda natureza nas séries iniciais agora se apresenta como uma situação de cálculo para os estudantes, quer dizer, uma readequação à própria lógica na qual não herdam o direito de entrar. 
Agora, esses alunos estão sozinhos e dependem da acumulação e do esforço (trabalho individual). Fala-se em cultivar-se para alcançar a próxima etapa. Estão na fase das múltiplas dimensões da condição juvenil, tais como os relacionamentos, a sociabilidade, a afirmação perante o grupo e, assim, “[...] com seus corpos e mentes condicionados para dar determinadas respostas a um conjunto de estímulos codificados" (FLEURI, 2008, p. 33). Para isso, superaram as características de origem e souberam reproduzir o discurso até agora, pois, é sem dúvida o produto acabado da amnésia da dominação social naturalizada nas estruturas mentais.

Com vistas à manutenção da sua dinâmica organizacional, percebe-se certa cumplicidade por parte dos agentes envolvidos no tocante à conservação das condições cognitivas diante da estrutura reproduzindo e naturalizando o caráter arbitrário do habitus secundário (a escola) que transcende os seus muros e tece os habitus primário (a família) e terciário (o trabalho) permitindo que "[...] se aplique com um sucesso crescente ao campo profissional (e também a outros) e, sobretudo, se conecte [...] às problemáticas da mudança social” (DUBAR, 2005, p. 17), definindo o indivíduo como uma “[...] espécie de tendência do grupo a perseverar no seu ser [...]” (DUBAR, 2005, p. 81). Próprio a isso, identificamos que a realidade é percebida não apenas como uma exterioridade objetiva, mas também como um esquema mental interiorizado que se torna consubstancia

\footnotetext{
[...] quando descobrem o que é comum, que não são iguais aos demais apesar do trabalho que realizam, só lhes resta duvidar de seu próprio valor, de sua própria igualdade. Eles só podem se auto responsabilizar, se sentir inferiores, o que lhes deixa a opção entre a retirada de um jogo em que estão perdendo e a violência, a destruição desse jogo. (DUBET, 2014, p. 16).
}

Observa-se uma espécie de pertencimento, tanto para os comuns quanto para aqueles que se destacam, o que verdadeiramente está em jogo é a afirmação de um habitus, já que “[...] o nobre permanece nobre mesmo que seja medíocre esgrimista (ao passo que o melhor esgrimista nem por isso é nobre)" (BOURDIEU, 2001, p. 49). O habitus, para Bourdieu (2001) não é uma imposição nem tampouco uma escolha; a concordância com o habitus está ligada a um campo social como se fosse uma escada simbólica daquele e para esse campo.

\section{ALGUMAS CONSIDERAÇÕES}

Deve-se ter em mente que não caem no colo do pesquisador os segredos relevantes da relação indivíduo/escola. No entanto, é possível percebê-los quando se submergem na gramática que escapa dos seus sujeitos, ainda que certas disposições de controle se encontrem 
cravadas nas entranhas do sistema escolar. Tal aspecto, confere força à hipótese levantada, isto é, ao construir uma análise dos agentes privilegiando os eu percurso. Tendo-se em vista a dificuldade inerente à análise empírica de separar o que no habitus do aluno pode ser creditado à família, já que normalmente é nela que estão os primeiros passos do sujeito e na preocupação com o cotidiano escolar, no qual se articulam disposições permanentes. As impressões aqui externadas despertaram interesse por conta de certas nuances observadas no comportamento dos alunos e professores das etapas pesquisadas que foi evidenciado o habitus como dispositivo atualizador e reestruturador de um esquema articulado. Notou-se que as saídas encontradas pelos alunos dos anos iniciais e finais assumem, em grande parte, significantes que transcendem o tempo histórico, “[...] cujas categorias de percepção e de apreciação (os sistemas de preferência) são o produto da história coletiva e individual (do agente social)" (BOURDIEU, 1997, p. 47). O espaço simbólico é que define o sentido da prática. Verificaram-se nos anos iniciais, por exemplo, comportamentos regulares, principalmente no que diz respeito à reativação das condutas a partir das conexões simbólicas com o mundo. Confirma-se também o empenho da escola com relação à legitimidade da linguagem e dos “[...] usos socialmente prescritos, caracterizando as práticas de uma coletividade ou de um grupo específico: linguagem, regras de polidez, comportamentos corporais, etc.” (BONNEWITZ, 2003, p. 76), que atendem às exigências de um determinado grupo. Essa materialidade do corpo evoca o sentido da compreensão da linguagem, à qual está presa como código de acesso ao sucesso nele contido, ou seja, "[...] numa aparente neutralidade prática a violência simbólica impondo, no caso aqui mencionado, um ensino homogêneo da língua pelos seus agentes" (BOURDIEU; PASSERON, 1982, p. 64) decretando assim que a língua coloquial da família é inapropriada para sala de aula. Sobre esse aspecto, fica mais evidente mostrar que os conteúdos dominantes dirigidos pela expressão escrita e falada convocam as representações exigidas na prática da linguagem, o que revela notadamente, que a cultura da língua deve ser apresentada de forma homogênea e ritualizada.

Essa cultura só se torna plena quando os códigos podem ser "[...] referenciados ao sistema escolar, o único capaz de consagrá-los e constituí-los, pelo exercício, como hábitos de pensamentos comuns a toda uma geração" (BOURDIEU, 2007, p. 208) como um verdadeiro ‘jeito' de agir dos agentes dentro do campo ou, de modo distinto, em oposição a esse jeito. Por isso que a coexistência de distintas concepções de mundo não significa que aja desacordo desvirtuado da funcionalidade do campo ou a dominação cultural e/ou ideológica pregada pelo reprodutivismo escolar, mas a enunciação radicada como menciona Mclaren 
(1992) por um ethos construído e incorporado por rituais escolares planificados para o nível do espaço/tempo em que se confirma o campo.

Com isso, certa aderência ao campo escolar por parte dos estudantes mostra que o ethos escolar como tempo, permite ações pouco reflexivas, ainda que no estágio dos anos finais da escolarização os estudantes não se mostrem tão dispostos a colaborarem com as disposições da escola, pois, a dominação nunca é por inteiro. Também é possível perceber que certas ressonâncias semânticas comumente produzidas por esse espaço como uma associação com reflexos mecânicos ou tendências fixas que respondem a formas idênticas de estímulos. O que nos sugere uma estrutura objetiva que forma um sujeito 'habitado' (preenchido), logo, esse sujeito pode ser percebido a partir da estrutura que o forma como sujeito verdadeiro (BOURDIEU; WACQUANT, 1992) mesmo que este tenha um poder de autorregulação.

A reprodução a partir do habitus, não acontece sem barreiras, tampouco é o produto final da escola; o aluno não é um fac-símile saído dos projetos escolares, mas um agente cognoscitivo capaz de reconhecer, reproduzir e atualizar-se diante da inscrição simbólica do habitus em um processo dialético e contínuo. É certo que essas dimensões não se separam senão por ênfases e nem para efeito avaliativo de um indivíduo ou de um grupo o fazem sem recorrer a instâncias mais específicas. O conhecimento ficcional dessas condições e da sua perpetuação é mais bem aproveitado se tornarmos sua subsistência possível a partir de um estudo do habitus que por sua vez, elabora plano o simbólico subjetivamente internalizado das ações. Assim, como o éter depende da eletricidade para se manifestar, o habitus depende da ação para se tornar visível. Quando o discurso afirma que a escola é para todos, deve-se rebatê-lo e dizer que a escola 'está em todos', ou melhor, forçosamente em todos.

\section{REFERÊNCIAS}

BERGER, P.; LUCKMANN, T. A construção social da realidade: tratado de sociologia do conhecimento. Petrópolis, RJ: Vozes, 2004.

BONNEWITZ, P. Primeiras lições sobre a sociologia de Pierre Bourdieu. Tradução: Lucy Magalhães. Petrópolis, RJ: Vozes, 2003.

BOURDIEU, P. A economia das trocas linguísticas. In: ORTIZ, R. (org.) Bourdieu Sociologia. São Paulo: Ática, 1983. (Coleção Grandes Cientistas Sociais, v. 39).

BOURDIEU, P. Questões de sociologia. Rio de Janeiro: Marco Zero, 1984.

BOURDIEU, P. O Poder Simbólico. Rio de Janeiro: Bertrand Brasil, 1989.

BOURDIEU, P. O Campo Econômico. Política e Sociedade, [S. l.], n. 6, p. 15-57, abr. 2005. Tradução: Suzana Cardoso e Cécile Raud-Matted. e-ISSN 2175-7984. DOI: 
https://doi.org/10.5007/\%25x. Originalmente publicado em Actes de La Rechercheen Sciences Sociales, n. 119, set. 1997. Disponível em: https://bit.ly/3pfQQk0. Acesso em: 20 set. 2020.

BOURDIEU, P. Coisas ditas. Tradução: Cássia R. da Silveira e Denise Moreno Pegorim. São Paulo: Brasiliense, 2004.

BOURDIEU, P. Meditações pascalianas. Rio de Janeiro: Bertrand Brasil, 2007.

BOURDIEU, P. Razões práticas. São Paulo: Papirus, 2008.

BOURDIEU, P. O senso prático. Paris: Les Éditions de Minuit, 2009.

BRANDÃO, Carlos Rodrigues. Pesquisa participante. 8. ed. São Paulo: Brasiliense, 1999.

CATANI, A. M. As possibilidades analíticas da noção de campo social. Educ. Soc. [online], Campinas, v. 32, n. 114, p. 189-202, jan./mar. 2011. Disponível em: https://bit.ly/2x4zdJD. Acesso em: 10 out. 2020.

DUBAR, C. A socialização - construção das identidades sociais e profissionais. São Paulo: Martins Fontes, 2005.

DUBET, F. Injustiças à experiência das desigualdades no trabalho. Florianópolis: UFSC, 2014.

DURKHEIM, E. Regras do método sociológico. 17. ed. Tradução: Maria Isaura Pereira de Queiroz. São Paulo: Companhia Editora Nacional, 2002.

ELIAS, N. O processo civilizador: formação do estado e civilização. Tradução: Ruy Jurgman. 2. ed. Rio de Janeiro: Jorge Zahar, 1993. v. 2.

GIL, A. C. Métodos e técnicas de pesquisa social. 5. ed. São Paulo: Atlas, 2006.

LAVAL, C. La Cage de Weber. Temporel: Revuelittéraire et artitisque, [S. l.], n. 2, 27 sep. 2006. Disponível em: http://temporel.fr/La-Cage-de-Weber. Acesso em: 27 out. 2020.

MAUSS, M. Sociologia e Antropologia. São Paulo: EDUSP, 1974.

MCLAREN, P. Rituais na escola. Em direção a uma economia política de símbolos e gestos na educação. Petrópolis, RJ: Vozes, 1992.

NOGUEIRA, C. M. M.; NOGUEIRA, M. A. A sociologia da educação de Pierre Bourdieu: limites e contribuições. Educação \& Sociedade, Campinas, v. 23, n. 78, p. 15-36, abr. 2002. DOI: https://doi.org/10.1590/S0101-73302002000200003. Disponível em: https://bit.ly/3uOBww2. Acesso em: 20 set. 2020.

SACRISTÁN, J. G. Poderes instáveis em Educação. Porto Alegre: Artes Médicas, 1999.

SETTON, M. G. J. A teoria do habitus em Pierre Bourdieu. Revista Brasileira de

Educação, Rio de Janeiro, n. 20, p. 60-70, ago. 2002. DOI: https://doi.org/10.1590/S141324782002000200005. Disponível em: https://bit.ly/3yXbie8. Acesso em: 20 set. 2020.

WEBER, M. Economia e Sociedade: fundamentos da sociologia compreensiva. Brasília, DF: UnB, 1999.

WEBER, M. Metodologia das Ciências Sociais. São Paulo: Cortez, 1995.

Weber, M. (2004). Ensaios de sociologia (W. Dutra, Trad.). Rio de Janeiro, RJ: Guanabara, Zahar Editores. 
WIDICK, R. F. Flesh and the free market: (On taking Bourdieu to the options exchange). In: SWARTZ, D.; ZOLBERG, V. L. (ed.). After Bourdieu: influence, critique, elaboration. Dordrecht, NED: Kluwer Academic Publisher, 2005. Disponível em: https://bit.ly/2CRPxmO. Acesso em: 10 out. 2020.

\section{THE INNATE AND LEARNED: THE EFFECTIVENESS OF THE NOTION OF HABITUS IN THE SCHOOL FIELD}

\section{ABSTRACT}

Although a lot has been researched about school, there are little explored aspects about the explicit or implicit actions that guide the practice of individuals in the school space. Therefore, this article intends to seek in Pierre Bourdieu (1930-2002) a sociological testimony from the theoreticalmethodological foundations of the social field and habitus as reflective means for understanding the daily performance to analyze school dispositions. Through the analysis of participant observation focusing on two classes from the early years and one class from the final years in two Public Schools in the Municipality of Blumenau, we established that the force of the habitus in a social field such as the school works as a capital, that is, as a socially recognized instrument in an appropriation linked to "symbolic" goods powerfully internalized through school practices. Reflection reveals that some learning processes are inserted through a perception based on practice transformed into customs, that is, inveterate behaviors prone to similar situations. It is, therefore, recognizable that the intentions and desires of individuals in the course of the schooling process manifest themselves recursively in the practice of the body, acting on themselves and on others.

KEYWORDS: Social field. School. Habitus. Symbolic.

\section{LO INNATO Y EL APRENDIZAJE: LA EFICACIA DE LA NOCIÓN DE HÁBITAT EN EL CAMPO ESCOLAR}

\section{RESUMEN}

Si bien se ha investigado mucho sobre la escuela, existen pocos aspectos explorados sobre las acciones explícitas o implícitas que orientan la práctica de los individuos en el espacio escolar. Por tanto, este artículo pretende buscar en Pierre Bourdieu (1930-2002) un testimonio sociológico desde los fundamentos teórico-metodológicos del campo social y del habitus como medio reflexivo para comprender el desempeño cotidiano para analizar las disposiciones escolares. A través del análisis de la observación participante enfocada en dos clases de los primeros años y una clase de los últimos años en dos Escuelas Públicas del Municipio de Blumenau, se estableció que la fortaleza del habitus en un campo social como es la escuela funciona como un el capital, es decir, como instrumento socialmente reconocido en una apropiación ligada a bienes "simbólicos" poderosamente internalizados a través de las prácticas escolares. La reflexión revela que algunos procesos de aprendizaje se insertan a través de una percepción basada en la práctica transformada en costumbres, es decir, comportamientos inveterados propensos a situaciones similares. Es, por tanto, reconocible que las intenciones y deseos de los individuos en el transcurso del proceso de escolarización se manifiestan de forma recursiva en la práctica del cuerpo, actuando sobre sí mismos y sobre los demás.

PALABRAS CLAVE: Campo social. Colegio. Habitus. Simbólico.

Submetido em: 26/07/2020

Aprovado em: 19/07/2021

Publicado em: 15/08/2021 